\title{
Effects of Orlistat/Phentermine versus Phentermine on Vascular Endothelial Cell Function in Obese and Overweight Adults: A Randomized, Double-Blinded, Placebo-Controlled Trial
}

This article was published in the following Dove Press journal:

Diabetes, Metabolic Syndrome and Obesity: Targets and Therapy

\author{
Yu-Jin Kwon (iD) ${ }^{1-3}$ \\ Hyangkyu Lee $\mathbb{D}^{4}$ \\ Chung Mo $\mathrm{Nam}^{5}$ \\ Hyuk-Jae Chang ${ }^{6}$ \\ Young-Ran Yoon ${ }^{7}$ \\ Hye Sun Lee $\mathbb{1 D}^{8}$ \\ Ji-Won Lee $\mathbb{D}^{\prime}$
}

'Department of Family Medicine, Yonsei University College of Medicine,

Severance Hospital, Seoul, Republic of

Korea; ${ }^{2}$ Department of Medicine,

Graduate School of Yonsei University

College of Medicine, Seoul, Republic of

Korea; ${ }^{3}$ Department of Family Medicine,

Yongin Severance Hospital, Yonsei

University College of Medicine, Yongin,

Republic of Korea; ${ }^{4}$ Yonsei University

College of Nursing, Mo-Im Kim Nursing

Research Institute, Seoul, Republic of

Korea; ${ }^{5}$ Department of Preventive

Medicine, Yonsei University College of

Medicine, Seoul, Republic of Korea;

${ }^{6}$ Department of Internal Medicine, Division

of Cardiology, Severance Cardiovascular

Hosp, Yonsei University College of Medicine,

Seoul, Republic of Korea; ${ }^{7}$ Department of

Molecular Medicine, School of Medicine,

Kyungpook National University, Daegu,

Republic of Korea; ${ }^{8}$ Biostatistics

Collaboration Unit, Department of

Research Affairs, Yonsei University College

of Medicine, Seoul, Republic of Korea

Correspondence: ji-Won Lee

Department of Family Medicine, Yonsei

University College of Medicine, Gangnam

Severance Hospital, 21 I Eonju-ro, Gangnam-

gu, 06273, Seoul, 135-720, Republic of Korea

Tel +82220193480

Fax +8234628209

Email indi5645@yuhs.ac
Background: In clinical practice, concomitant treatment of orlistat with phentermine is commonly used off-label. However, clinical trials have not been performed to evaluate whether their combination improves metabolic parameters and cardiovascular risk factors other than weight loss. Therefore, we aimed to compare the efficacy of concomitant administration of orlistat and phentermine versus phentermine alone on the endothelial cell function in overweight and obese adults with back pain.

Methods: We conducted a 12-week, double-blinded, placebo-controlled clinical trial involving 114 patients with a body mass index of $\geq 30$ (obese) or $\geq 27$ (overweight) with weightrelated comorbidities. We randomly assigned patients in a 1:1 ratio to receive orlistat (120mg) three times daily and phentermine $(37.5 \mathrm{mg}$ ) once daily, or a placebo three times daily and phentermine (37.5mg) once daily. Primary endpoint was changes in endotheliumdependent vasodilatation measured using ultrasound assessment of flow-mediated dilatation (FMD). Differences within groups after intervention were compared using the paired $t$-test or Wilcoxon signed-rank test. Differences in changes between the groups were calculated using an analysis of covariance after adjusting for each baseline value.

Results: Mean weight loss during the 12 -week study period was $6.1 \mathrm{~kg}$ in the orlistat/phentermine group and in the placebo/phentermine group. Adjusted mean changes in total and non-high-density lipoprotein cholesterol were significantly greater in the orlistat/phentermine group than in the placebo/phentermine group. Adjusted mean changes in endothelium-dependent FMD were significantly greater in the orlistat/phentermine group than in the placebo/phentermine group (4.97 $\pm 0.98 \%$ vs $2.05 \pm 0.99 \%$, respectively; $\mathrm{p}=0.038$ ). Changes in endothelium-independent nitroglycerin-mediated dilatation were not significantly different between the groups.

Conclusion: Orlistat/phentermine significantly improved the vascular endothelial cell function compared with phentermine alone. Orlistat might have beneficial effects on the decrease of the risk of cardiovascular disease, especially in overweight and obese patients with comorbidities.

Trial Registration: ClinicalTrails.gov number, NCT03675191.

Keywords: obesity, orlistat, phentermine, endothelial cell function

\section{Introduction}

The prevalence of obesity is gradually increasing globally; ${ }^{1}$ in Korea, its prevalence has increased from $29.7 \%$ in 2009 to $32.4 \%$ in $2015 .^{2}$ The incidence of cardiovascular diseases (CVDs) has also increased with the prevalence of obesity. 
The endothelium, which is composed of a monolayer of endothelial cells, maintains vascular homeostasis by producing and releasing vasoactive molecules. ${ }^{3}$ Because the endothelium regulates the micro- and macrocirculation of blood flow, endothelial dysfunction is considered to be an early indicator of CVD. ${ }^{4}$ Obesity and its related comorbidities, such as hypertension and hypercholesterolemia, are risk factors for endothelial cell dysfunction, ${ }^{5}$ whereas weight loss and improvement of metabolic parameters through lifestyle modifications improve endothelial cell function. ${ }^{6}$ Several studies also showed that pharmacological treatments such as statin and saxagliptin have a beneficial effect on endothelial function., ${ }^{7,8}$

Phentermine hydrochloride $(\mathrm{HCl})$, a sympathomimetic amine, is the most commonly prescribed anti-obesity drug in the United States and other countries. ${ }^{9}$ The short-term efficacy of phentermine has been demonstrated in terms of weight loss and improved metabolic parameters. ${ }^{10}$ However, concerns of increased heart rate (HR) and blood pressure (BP) related to its sympathomimetic effects remain. ${ }^{11}$ Orlistat, a gastric and pancreatic lipase inhibitor without effects on the central nervous system has been approved for several years for long-term weight management. ${ }^{12}$ Combined with lifestyle modification, orlistat treatment is associated with small, but meaningful weight loss, and reductions in BP and total cholesterol (TC) and low-density lipoprotein cholesterol (LDL-C). ${ }^{13}$ In addition, several studies have reported the anti-inflammatory, antioxidant, and antitumor effects of orlistat. ${ }^{14,15}$

Owing to their differing pharmacology, the concomitant treatment of orlistat with phentermine is commonly used off-label in clinical practice. ${ }^{16}$ However, no clinical trials have been conducted to assess whether the combination therapy of these two drugs improves metabolic parameters and cardiovascular risk factors other than weight loss. We investigated that adding orlistat to phentermine has a positive effect on endothelial cell function compared with phentermine alone in obese and overweight adults with weight-related comorbidities.

\section{Methods}

\section{Study Design and Patients}

This study was a randomized, double-blinded, placebocontrolled 12-week clinical trial. The protocol was approved by the institutional review board of Yongin Severance Hospital (IRB No. 9-2018-0004) and registered with ClinicalTrails.gov (number: NCT03675191). This study was performed in compliance with the Declaration of Helsinki. Written consent was obtained from all patients prior to participation.

Patients were recruited from October 2018 to May 2019 at Yongin Severance Hospital (Yongin, South Korea). Eligible patients aged 20-70 years were obese (body mass index $[\mathrm{BMI}] \geq 30 \mathrm{~kg} / \mathrm{m}^{2}$ ) or overweight $\left(\mathrm{BMI} \geq 27 \mathrm{~kg} / \mathrm{m}^{2}\right)$ with at least one weight-related complication (eg, diabetes, prediabetes, hypertension, dyslipidemia, or metabolic syndrome). Exclusion criteria included the following contraindications for the use of phentermine or orlistat (Supplementary information).

\section{Randomization and Masking}

Participants were randomly assigned in a 1:1 ratio to receive a placebo three times a day plus phentermine $\mathrm{HCl}(37.5 \mathrm{mg})$ once daily, or orlistat $(120 \mathrm{mg})$ three times a day plus phentermine $\mathrm{HCl}(37.5 \mathrm{mg})$ once daily. Subjects were instructed that if they a skipped meal, they should also skip the corresponding orlistat dose. Randomization was performed using a centralized computer-generated system. Investigators and patients were masked to treatment assignment throughout the study.

\section{Procedures and Endpoints}

Study visits were scheduled at screening; baseline; and at 4, 8, and 12 weeks. Body weight, waist circumference (WC), systolic and diastolic BP were measured at each visit. Laboratory tests, HR variability, body composition measurement, and flow-mediated dilatation (FMD) were measured at baseline and 12 weeks. Health-related (physical activity, smoking, alcohol consumption) and food intake (using a 24-h recall method) questionnaires were administered at baseline and 12 weeks. Participants were categorized into never smoker, ex-smoker, and current smoker groups. An alcohol drinker was defined as a person who drinks alcohol more than once a month. Physical activity was defined as undertaking light to moderate exercise more than two times per week. We used a binary variable with the presence or absence of a history of hypertension, dyslipidemia, or diabetes, according to a self-reported questionnaire.

Weight and body composition (skeletal muscle mass, fat mass, and percent body fat) were assessed by conducting bioelectrical impedance analysis using the Inbody720 body composition analyzer (Biospace, Seoul, South Korea). WC was measured using a measuring tape on the horizontal plane midway between the lowest rib and iliac crest. 
Blood samples were obtained after more than 8 $\mathrm{h}$ fasting. At each visit, all participants were consulted about their diet and exercise by a doctor and advised to follow a hypocaloric diet (consuming 500 kcal below individual estimated energy requirements per day) and light- ( $\sim 3$ metabolic equivalent) to moderate-intensity exercise (3-6 metabolic equivalent) more than three times per week.

The primary efficacy endpoint was changed in FMD based on ultrasound assessment. Secondary endpoints were changed in weight, WC, BMI, fat mass, fat, percentage, serum lipid levels, C-reactive protein (CRP), and glycemic variables (fasting glucose, fasting insulin, HOMA-IR).

\section{Safety and Compliance}

Safety assessment consisted of the assessment of adverse events and use of concomitant medications, measurement of vital signs (BP, HR), laboratory tests (aspartate aminotransferase [AST], alanine aminotransferase [ALT], serum creatinine $[\mathrm{Cr}]$ ), and echocardiography. Adverse events and the use of concomitant medications were assessed and vital signs were measured at each visit. A trained and certified sonographer conducted all echocardiography examinations using the SSH$880 \mathrm{CV}$ ultrasound system (Artida, Tokyo, Japan) at screening and 12 weeks. A cardiologist supervised and interpreted the results. Drug compliance was measured by counting the remaining pills at each visit. The compliance rate was set at $>70 \%$. For orlistat, the compliance rate was determined after taking into consideration the number of meals skipped.

\section{Assessment of the Vascular Endothelial Cell Function}

Endothelium-dependent FMD was assessed according to the guidelines for the ultrasound assessment of endothelial-dependent flow-mediated vasodilatation of the brachial artery introduced by the International Brachial Artery Reactivity Task Force. ${ }^{17}$ FMD was conducted after 8-12 $\mathrm{h}$ of fasting in a quiet, temperature-controlled room. Patients were not permitted to take antihypertensive medication (calcium channel blocker, nitrate, beta-blocker, angiotensin-converting-enzyme inhibitor, angiotensin II receptor blockers) within $48 \mathrm{~h}$ and aspirin and nonsteroidal anti-inflammatory drugs within 10 days before FMD. Patients were not permitted to consume caffeine or smoke within $8 \mathrm{~h}$ before FMD. A sphygmomanometer cuff was placed above the antecubital fossa on the forearm and inflated to at least $50 \mathrm{mmHg}$ above patients' SBP. Images of the brachial artery were recorded before inflation and at $30 \mathrm{~s}, 45 \mathrm{~s}, 60 \mathrm{~s}, 75 \mathrm{~s}$, and $90 \mathrm{~s}$ after deflation of the cuff. After a 10 -min rest, $0.6 \mathrm{mg}$ of sublingual nitroglycerin was administered, and endothelium-independent dilatation was assessed. Images were obtained before nitroglycerin administration and at 3 and 4 min after nitroglycerin administration. Endothelium-dependent (FMD) and endothelium-independent (nitroglycerinmediated dilatation, NMD) vasodilatation were calculated as follows: FMD (\%) or NMD $(\%)=([$ maximal diameter - baseline diameter $] /$ baseline diameter $) \times 100$. The same blinded investigator performed all FMD assessments. The intraclass correlation coefficient was $0.979(0.970-0.985)$.

\section{Statistical Analysis}

We conducted the Kolmogorov-Smirnov test of normality to examine the normal distribution of values before analysis. Data are presented as mean \pm standard deviations or median (interquartile ranges). For efficacy analyses, we used data from the full analysis set, which included all patients who underwent randomization and had at least one assessment. Missing values were imputed using the last-observation-carried-forward method. Differences in baseline characteristics between the placebo/phentermine and orlistat/phentermine groups were compared using the independent $t$-test or Mann-Whitney $U$-test. Differences after intervention within groups were compared using the paired $t$-test or Wilcoxon signed-rank test. Differences in changes between the groups were calculated using an analysis of covariance after adjusting for each baseline value. Significance tests were two-sided, with an alpha value of 0.05 . All statistical analyses were performed using SPSS software version 25.0 (IBM Corp., Armonk, NY, USA).

For the calculation of sample size, no randomized controlled trial has been performed to investigate the effect of orlistat on the endothelial cell function using FMD. Because LDL-C was reported to be significantly correlated with FMD in previous studies, ${ }^{18,19}$ we calculated the effect size based on absolute LDL-C changes between the orlistat $(-0.53 \pm 0.65)$ and placebo/phentermine $(-0.09 \pm 0.8$; effect size $=0.6)$ groups. ${ }^{20}$ We assumed that the effect size would be similar to the effect size of FMD. A Cohen's effect size of 0.6 indicates a medium to large effect size. Sample size was calculated using an independent two-sample $t$-test with $80 \%$ power, a two-sided significance level of $5 \%$, and a dropout rate of $20 \%$. 


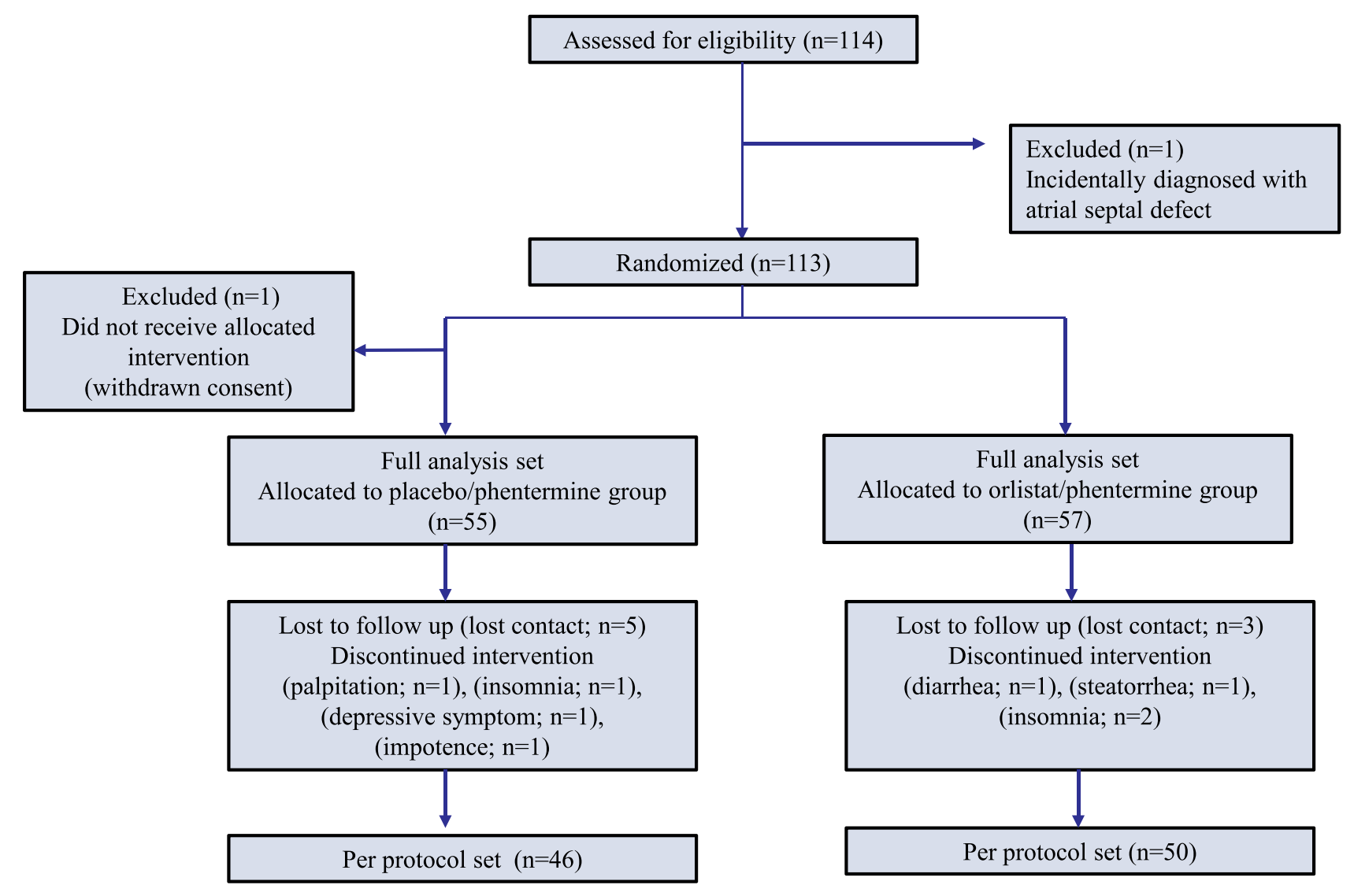

Figure I Flow chart of study cohort enrollment, allocation, follow-up, and completion.

\section{Results}

Subject disposition is shown in Figure 1. A total of 113 subjects were randomized to receive placebo/phentermine $(\mathrm{N}$ $=56)$ or orlistat/phentermine $(\mathrm{N}=57)$. Of these, 96 subjects (46 assigned to placebo/phentermine, and 50 assigned to orlistat/phentermine) completed the full 12-week trial.

Baseline characteristics were also similar between the orlistat/phentermine $(n=57)$ and placebo/phentermine $(n=55)$ groups in terms of age, sex, and BMI, and metabolic parameters and FMD values were well-balanced between the groups (Table 1).

Table 2 shows the characteristics and changes in the two groups before and after intervention after adjusting for each baseline value. Both treatments led to clinically significant weight loss $(-6.1 \mathrm{~kg}$ vs $-6.0 \mathrm{~kg} ; \mathrm{p}=0.94)$. Body composition measures (fat mass, percent fat, and fat-free mass) and WC decreased in both groups. SBP and DBP decreased and HR increased slightly in both treatment groups. Fasting insulin levels and HOMA-IR were significantly decreased in both groups. However, fasting glucose levels were not altered in both groups. Adjusted mean changes in anthropometric measurements (weight,
WC, fat mass, percent body fat), BP, CRP, glucose, insulin, HOMA-IR, and caloric intake were not different between the two groups after adjusting for each baseline value.

Table 3 shows the adjusted mean changes in the concentrates of lipids and FMD. Changes in TC and non-HDL-C were significantly greater in the orlistat/phentermine group than in the placebo/phentermine group $(-0.62 \pm 0.07 \mathrm{mmol} / \mathrm{l} \mathrm{vs}-0.32$ $\pm 0.07 \mathrm{mmol} / \mathrm{l}$, respectively, $\mathrm{p}=0.01 ;-0.53 \pm 0.07 \mathrm{mmol} / \mathrm{l} \mathrm{vs}$ $-0.30 \pm 0.07 \mathrm{mmol} / 1$, respectively, $\mathrm{p}=0.02$ ). Although no statistical significance was found, adjusted mean LDL was further decreased in the orlistat/phentermine group than in the placebo/phentermine group $(-0.36 \pm 0.05 \mathrm{mmol} / \mathrm{l}$ vs $-0.21 \pm 0.06$ $\mathrm{mmol} / \mathrm{l}, \mathrm{p}=0.05)$. Adjusted mean changes in $\mathrm{TG}$ were not significantly different between the groups. Adjusted mean changes in endothelium-dependent FMD were significantly greater in the orlistat/phentermine group than in the placebo/ phentermine group $(4.97 \pm 0.98 \%$ vs $2.05 \pm 0.99 \%$, respectively; $\mathrm{p}=0.04$ ), whereas changes in endothelium-independent NMD were not significantly different between the groups.

Changes in lipids, FMD, and NMD were similar in the per protocol set $(\mathrm{n}=96)$ (Supplementary Table 1). 
Table I Baseline Characteristics of Study Participants

\begin{tabular}{|c|c|c|c|}
\hline \multirow[t]{2}{*}{$\mathbf{N}$} & \multirow{2}{*}{$\begin{array}{l}\text { Placebo/Phentermine } \\
55\end{array}$} & \multirow{2}{*}{$\begin{array}{l}\text { Orlistat/Phentermine } \\
57\end{array}$} & \multirow[t]{2}{*}{ p-value } \\
\hline & & & \\
\hline Women, No (\%) & $43(78.6)$ & $44(77.2)$ & 0.86 \\
\hline Age, years & $46.0 \pm 11.3$ & $45.5 \pm 12.5$ & 0.84 \\
\hline \multicolumn{4}{|l|}{ Physical measurement } \\
\hline Height, cm & $163.0 \pm 9.0$ & $164.0 \pm 9.6$ & 0.56 \\
\hline Weightf, kg & $78.3(72.2,90.5)$ & $80.3(72.6,96.3)$ & 0.56 \\
\hline Body mass index, $\mathrm{kg} / \mathrm{m}^{2} \dagger$ & $29.8(27.6,33.6)$ & $30.8(28.1,33.5)$ & 0.42 \\
\hline Waist circumference, cm & $102.8 \pm 9.5$ & $104.1 \pm 9.5$ & 0.47 \\
\hline Fat free mass, kg† & $47.3(42.7,53.9)$ & $47.7(42.1,59.5)$ & 0.69 \\
\hline Fat mass, kg $\dagger$ & $30.5(28.5,37.1)$ & $32.4(28.0,39.5)$ & 0.52 \\
\hline Percent body fat, \% & $39.9 \pm 5.7$ & $40.0 \pm 6.9$ & 0.99 \\
\hline Waist hip ratio & $0.95(0.93,0.97)$ & $0.95(0.93,0.98)$ & 0.73 \\
\hline $\mathrm{SBP}(\mathrm{mmHg})$ & $128.6 \pm 14.2$ & $127.8 \pm 15.5$ & 0.79 \\
\hline $\mathrm{DBP}(\mathrm{mmHg})$ & $86.3 \pm 12.5$ & $85.6 \pm 11.7$ & 0.78 \\
\hline Heart rate (bpm) & $72.8 \pm 8.8$ & $71.8 \pm 9.5$ & 0.55 \\
\hline \multicolumn{4}{|l|}{ Comorbid condition, n (\%) } \\
\hline HTN & $33(58.9)$ & $30(52.6)$ & 0.50 \\
\hline Diabetes & $6(10.7)$ & $12(2||)$. & 0.13 \\
\hline Hypercholesterolemia & $22(39.3)$ & $16(28.1)$ & 0.21 \\
\hline \multicolumn{4}{|l|}{ Medication history } \\
\hline HTN medication & $13(23.2)$ & II (19.3) & 0.61 \\
\hline Diabetes medication & $4(7.1)$ & $6(10.5)$ & 0.53 \\
\hline Dyslipidemia medication & $13(23.2)$ & $9(15.8)$ & 0.32 \\
\hline \multicolumn{4}{|l|}{ Health-related behavior } \\
\hline Smoking, n (\%) & & & 0.72 \\
\hline Non-smoker & $30(66.7)$ & $35(70.0)$ & \\
\hline Ex-smoker & $8(17.8)$ & $6(12.0)$ & \\
\hline Current smoker & $7(15.6)$ & $9(18.0)$ & \\
\hline Alcohol consumption, $\mathrm{n}(\%)$ & $21(47.7)$ & $26(54.2)$ & 0.54 \\
\hline Total calorie intake (kcal) & $1522(1160,1739)$ & I 458.7 (I238, I294) & 0.69 \\
\hline \multicolumn{4}{|l|}{ Laboratory test } \\
\hline 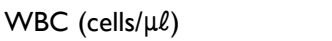 & $6662 \pm 173$ & $6577 \pm 173$ & 0.79 \\
\hline
\end{tabular}


Table I (Continued).

\begin{tabular}{|c|c|c|c|}
\hline \multirow[t]{2}{*}{$\mathbf{N}$} & Placebo/Phentermine & Orlistat/Phentermine & \multirow[t]{2}{*}{ p-value } \\
\hline & 55 & 57 & \\
\hline CRP (mg/L) & I.25 $(0.73,2.08)$ & $1.50(0.60,2.70)$ & 0.92 \\
\hline AST (IU/L) & $24.0(19.3,30.8)$ & $25.0(19.0,33.5)$ & 0.57 \\
\hline ALT (IU/L) & $25.0(\mid 7.3,31.8)$ & $25.0(15.5,44.0)$ & 0.47 \\
\hline Serum creatinine (mg/dl) & $0.75(0.68,0.86)$ & $0.73(0.68,0.87)$ & 0.72 \\
\hline Glucose (mmol/l) & $5.6 \mathrm{I}(5.38,6.1 \mathrm{I})$ & $5.72(5.33,6.43)$ & 0.27 \\
\hline Insulin (mU/L) & $8.65(6.88,12.98)$ & $8.20(5.60,12.85)$ & 0.40 \\
\hline HOMA-IR & $2.27(1.77,3.49)$ & $2.05(1.39,3.66)$ & 0.71 \\
\hline Triglyceride (mmol/l) & $1.47(1.04,1.78)$ & $1.36(0.98,1.68)$ & 0.62 \\
\hline Total cholesterol (mmol/l) & $5.33 \pm 1.04$ & $5.02 \pm 0.92$ & 0.10 \\
\hline LDL cholesterol (mmol/l) & $3.40 \pm 0.80$ & $3.10 \pm 0.62$ & 0.02 \\
\hline Non-HDL cholesterol $(\mathrm{mmol} / \mathrm{l})$ & $4.00 \pm 1.03$ & $3.66 \pm 0.88$ & 0.07 \\
\hline HDL cholesterol (mmol/l) & $1.34 \pm 0.23$ & $1.36 \pm 0.33$ & 0.08 \\
\hline \multicolumn{4}{|l|}{ Flow-mediated dilatation } \\
\hline FMD (\%) & $11.2 \pm 5.4$ & $10.6 \pm 6.1$ & 0.56 \\
\hline NMD (\%) & $10.4 \pm 7.3$ & $9.6 \pm 6.2$ & 0.62 \\
\hline
\end{tabular}

Notes: Data are presented as mean \pm standard deviations, median (interquartile ranges), or number (percentage); $\mathrm{p}$-values calculated using independent two-sample $t$-test or Mann-Whitney $U$-test; ${ }^{\dagger}$ Continuous values calculated using Mann-Whitney U-test, and categorical values calculated using chi-square test.

Abbreviations: SBP, systolic blood pressure; DBP, diastolic blood pressure; HTN, hypertension; WBC, white blood cell; CRP, C-reactive protein; AST, aspartate aminotransferase; ALT, alanine aminotransferase; HOMR-IR, homeostasis model assessment of insulin resistance; LDL-C, low-density lipoprotein cholesterol; HDL-C, highdensity lipoprotein cholesterol; FMD, flow-mediated dilatation; NMD, nitroglycerin-mediated dilatation.

\section{Adverse Events}

Percentages of patients with adverse events in the full analysis set were similar between the placebo/phentermine $(n=18$ [32.1\%]) and orlistat/phentermine $(n=23$ [40.4\%]) groups (Supplementary Table 2). Safety was measured using BP, HR, and echocardiography. Echocardiography showed no valvular heart diseases, pulmonary artery hypertension, or other significant findings (Supplementary Table 3).

\section{Discussion}

In this randomized, double-blinded, placebo-controlled study, we found that endothelial-dependent FMD significantly improved in the orlistat/phentermine group compared with the placebo/phentermine group in obese and overweight patients with comorbidities.

In this study, mean weight loss was decreased by approximately $6 \mathrm{~kg}$ in both groups, which indicates that the concomitant treatment of orlistat with phentermine does not provide additive weight loss effects. Our findings are similar to those of previous studies that reported weight loss in orlistat plus sibutramine vs sibutramine alone. ${ }^{21,22}$ Moreover, WC, BP, CRP, and insulin levels were significantly improved in both groups, and adjusted mean changes were similar between the groups. We believe that these metabolic parameters were mainly affected by weight loss. Further, HDL-C significantly decreased in the orlistat/phentermine group. Although the exact reason for this decrease in HDL in the orlistat/phentermine group is unclear, HDL-C simultaneously decreases with decreasing serum cholesterol because orlistat inhibits intestinal fat digestion and dietary fat absorption by approximately $30 \%{ }^{23}$

In contrast to previous studies that focused on weight loss as a primary endpoint, we investigated the effect of concomitant therapy with orlistat and phentermine on the endothelial cell function. The orlistat plus phentermine group, along with mild exercise and calorie reduction, showed greater improvement in FMD in overweight and obese adults than the phentermine alone group. 


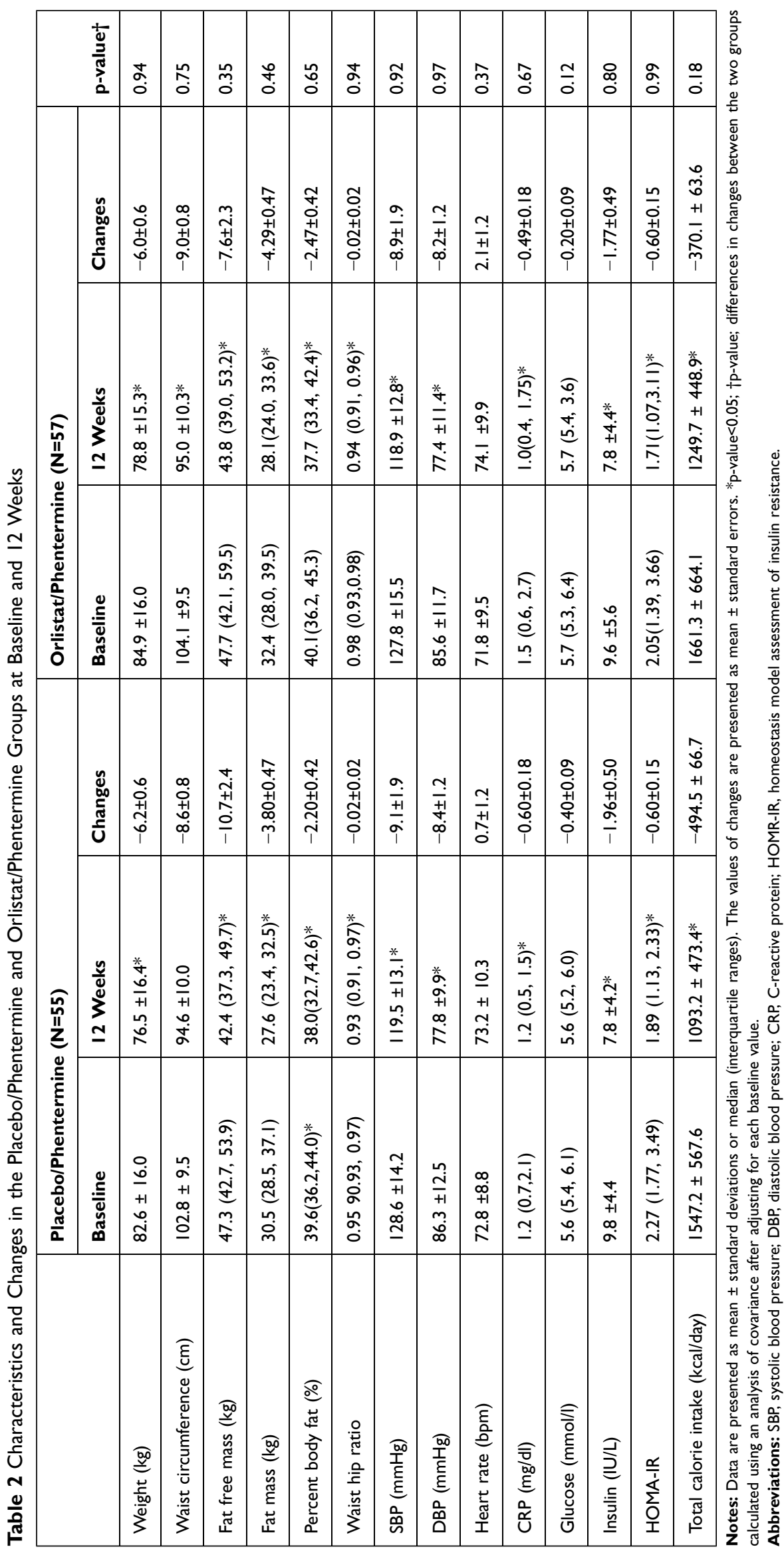


Table 3 Changes in Lipids and Endothelial Cell Function in the Placebo/Phentermine and Orlistat/Phentermine Groups at Baseline and 12 Weeks

\begin{tabular}{|l|l|l|l|l|l|l|l|}
\hline & \multicolumn{3}{|l}{ Placebo/Phentermine (N=55) } & \multicolumn{2}{l|}{ Orlistat/Phentermine (N=57) } \\
\cline { 2 - 8 } & Baseline & 12 Weeks & Changes & Baseline & I2 Weeks & Changes & p-value $\dagger$ \\
\hline Triglyceride & $1.47(1.04, I .78)^{*}$ & $1.13(0.93,1.47)^{*}$ & $-0.35 \pm 0.08$ & $1.36(0.98,1.68)$ & $1.18(0.82,1.59)^{*}$ & $-0.42 \pm 0.08$ & 0.55 \\
\hline Total cholesterol & $5.33 \pm 1.04$ & $4.96 \pm 1.00^{*}$ & $-0.32 \pm 0.07$ & $5.02 \pm 0.92$ & $4.45 \pm 0.75^{*}$ & $-0.62 \pm 0.07$ & 0.01 \\
\hline LDL cholesterol & $3.40 \pm 0.80$ & $3.15 \pm 0.76^{*}$ & $-0.21 \pm 0.06$ & $3.10 \pm 0.62$ & $2.78 \pm 0.55^{*}$ & $-0.36 \pm 0.05$ & 0.05 \\
\hline Non-HDL cholesterol & $3.99 \pm 1.04$ & $3.64 \pm 0.96^{*}$ & $-0.30 \pm 0.07$ & $3.66 \pm 0.88$ & $3.18 \pm 0.69 *$ & $-0.53 \pm 0.07$ & 0.02 \\
\hline HDL cholesterol & $1.33 \pm 0.24$ & $1.32 \pm 0.23$ & $-0.03 \pm 0.02$ & $1.36 \pm 0.33$ & $1.27 \pm 0.26^{*}$ & $-0.09 \pm 0.02$ & 0.01 \\
\hline FMD (\%) & $11.2 \pm .5 .4$ & $13.0 \pm 6.6$ & $2.05 \pm 0.99$ & $10.6 \pm 6.1$ & $15.8 \pm 8.2^{*}$ & $4.97 \pm 0.98$ & 0.04 \\
\hline NMD (\%) & $12.7 \pm 6.3$ & $14.3 \pm 6.0$ & $1.09 \pm 0.86$ & $11.0 \pm 5.5$ & $13.0 \pm 6.3$ & $2.49 \pm 0.83$ & 0.70 \\
\hline
\end{tabular}

Notes: Data are presented as mean \pm standard deviations or median (interquartile ranges). The values of changes are presented as mean \pm standard errors. ${ }^{*} \mathrm{p}-\mathrm{value}<0.05$; tp-value; differences in changes between the two groups calculated using an analysis of covariance after adjusting for each baseline value.

Abbreviations: LDL-C, low-density lipoprotein cholesterol; HDL-C, high-density lipoprotein cholesterol; FMD, flow-mediated dilatation; NMD, nitroglycerin-mediated dilatation.

Previous studies have shown the positive role of orlistat in endothelial cell function. Sekuri et $\mathrm{al}^{24}$ and Liu et $\mathrm{al}^{25}$ showed that orlistat treatment improves FMD in young obese women (aged 18-34 years) and obese adults with hypertension. Bergholm et al's randomized controlled trial ${ }^{6}$ showed that orlistat treatment improves endothelium-dependent vasodilatation using a blood flow response to acetylcholine in obese women with gestational diabetes, despite similar weight loss reported in the orlistat and placebo groups. We also hypothesized that adding orlistat could improve endotheliumdependent vasodilatation regardless of weight loss. In this study, endothelium-dependent FMD was significantly improved in the orlistat/phentermine group only. NMD was not significantly affected in either group, indicating that orlistat has a positive role in the endothelium.

In the early stages when blood vessel is under shear stress, a calcium-activated potassium channel in the endothelium is opened, which activates endothelial nitric oxide synthase (eNOS) and leads to increased NO production to protect vessel damage. ${ }^{17}$ However, prolonged endothelial shear stress reduces the bioavailability of NO by decreasing eNOS mRNA and protein expression and promoting oxidative stress and proinflammatory cytokines. ${ }^{26,27}$ Inflammation has been known to decrease the endothelial cell function and a key factor in pathophysiology in obesity and CVD. ${ }^{28}$ While the exact mechanism involved in our results is unclear, the antiinflammatory and anti-cancer effects of orlistat could be possible explanations. Samuelsson et $\mathrm{al}^{29}$ reported that orlistat treatment for 1 year significantly reduced tumor necrosis factor alpha levels, a potent inflammatory mediator, compared with placebo treatment. In our study, CRP tended to be reduced more in the orlistat/phentermine group than in the placebo/ phentermine group. However, no significant differences were found in CRP reduction in both groups, which might be due to the short duration of orlistat treatment. A long-term study is warranted to clarify the change in CRP and anti-inflammatory effects of orlistat.

Another explanation of the effects of orlistat on the endothelial cell function is that orlistat is a novel fatty acid synthase inhibitor. ${ }^{14,15} \mathrm{~A}$ previous study revealed that elevated free fatty acids (FFAs) are related to impaired endothelial cell function. ${ }^{30}$ FFA not only reduces NO production in endothelial cells by downregulating the AMPK/PI3K/Akt/eNOS signaling ${ }^{31}$ but also disrupts calcium signaling-mediated NO production. ${ }^{32}$ FFA, per se, is a source of reactive oxygen species, which leads to oxidative stress that impairs the endothelium. ${ }^{33}$ Therefore, orlistat treatment could lead to an improvement in endothelial functions and vasodilatation.

Finally, despite identical weight loss between the groups, we found that the orlistat/phentermine group had a greater reduction of TC and non-HDL and a mild, but greater, reduction of LDL cholesterol than the placebo/phentermine group. Feron et al ${ }^{34}$ showed that hypercholesterolemia decreases NO production in the endothelium by upregulating caveolin protein and inhibiting eNOS activity. Therefore, in hypercholesterolemia, reduced bioavailability of NO leads to impairment of endothelium-dependent vasodilation. Thus, reduction of serum cholesterol might have led to the improvement in the endothelial cell function observed in this study. 
This study has some limitations. This study has some limitations. First, although FMD is known as a standard tool for the noninvasive assessment of conduit artery endothelial function, it requires highly trained technicians and could be affected by temperature and environmental factors. Therefore, a skilled investigator conducted FMD in a quiet and dark room in this study. Second, the treatment duration (12 weeks) was relatively short. Third, this study included Korean subjects only; therefore, our results may not be generalizable to different ethnicities. Fourth, there was no treatment group that received placebo only.

\section{Conclusions}

This study demonstrated that orlistat improves endothelialdependent FMD in obese adults independent of weight loss. Adding orlistat to phentermine could be helpful for reducing cardiovascular risk by improving the endothelial cell function, particularly in overweight patients with comorbidities or obese patients. More data about the concomitant treatment of orlistat with phentermine are needed.

\section{Abbreviations}

BMI, body mass index; BP, blood pressure; CRP, C-reactive protein; CVD, cardiovascular disease; DBP, diastolic blood pressure; eNOS, endothelial nitric oxide synthase; FFA, free fatty acid; FMD, flow-mediated dilatation; HDL-C, highdensity lipoprotein cholesterol; HOMA-IR, homeostasis model assessment of insulin resistance; HR, heart rate; LDLC, low-density lipoprotein cholesterol; NMD, nitroglycerinmediated dilatation; SBP, systolic blood pressure; TC, total cholesterol; VAS, visual analog scale; WBC, white blood cell; WC, waist circumference.

\section{Data Sharing Statement}

The datasets used and/or analysed during the current study are available from the corresponding author on reasonable request.

\section{Ethics Approval and Consent to Participate}

The protocol was approved by the institutional review board of Yongin Severance Hospital (IRB No. 9-20180004) and registered with ClinicalTrails.gov (number: NCT03675191). This study was performed in compliance with the Declaration of Helsinki. Written consent was obtained from all patients prior to participation.

\section{Author Contributions}

All authors made substantial contributions to conception and design, acquisition of data, or analysis and interpretation of data; took part in drafting the article or revising it critically for important intellectual content; agreed to submit to the current journal; gave final approval of the version to be published; and agree to be accountable for all aspects of the work.

\section{Funding}

This study was supported by research grants from Hanmi Pharmaceutical Co., Ltd. (J.W.L), the institute for information \& communications technology promotion (IITP) grant funded by the Korea government (MSIT) (2019-31-1293, Autonomous digital companion framework and application) (H.J.C) and by a 2018 faculty research grant from Yonsei University College of Medicine [6-2018-0090] to Y.J.K. The funders had no role in study design, data collection and analysis, decision to publish, or preparation of the manuscript.

\section{Disclosure}

The authors have nothing to declare.

\section{References}

1. Afshin A, Forouzanfar MH, Reitsma MB, et al. Health effects of overweight and obesity in 195 countries over 25 years. $N$ Engl J Med. 2017;377(1):13-27. doi:10.1056/NEJMoa1614362

2. Seo MH, Lee WY, Kim SS, et al. 2018 Korean society for the study of obesity guideline for the management of obesity in Korea. $J$ Obes Metab Syndr. 2019;28(1):40-45. doi:10.7570/jomes.2019.28.1.40

3. Deanfield JE, Halcox JP, Rabelink TJ. Endothelial function and dysfunction: testing and clinical relevance. Circulation. 2007;115 (10):1285-1295. doi:10.1161/circulationaha.106.652859

4. Yeboah J, Folsom AR, Burke GL, et al. Predictive value of brachial flow-mediated dilation for incident cardiovascular events in a population-based study: the multi-ethnic study of atherosclerosis. Circulation. 2009;120(6):502-509. doi:10.1161/circulationah a.109.864801

5. Meyers MR, Gokce N. Endothelial dysfunction in obesity: etiological role in atherosclerosis. Curr Opin Endocrinol Diabetes Obes. 2007;14 (5):365-369. doi:10.1097/MED.0b013e3282be90a8

6. Bergholm R, Tiikkainen M, Vehkavaara S, et al. Lowering of LDL cholesterol rather than moderate weight loss improves endothelium-dependent vasodilatation in obese women with previous gestational diabetes. Diabetes Care. 2003;26(6):1667-1672. doi:10.2337/diacare.26.6.1667

7. Nakamura T, Uematsu M, Yoshizaki T, Kobayashi T, Watanabe Y, Kugiyama K. Improvement of endothelial dysfunction is mediated through reduction of remnant lipoprotein after statin therapy in patients with coronary artery disease. $J$ Cardiol. 2020;75(3):270-274. doi:10.1016/j.jjcc.2019.08.006

8. Dell'Oro R, Maloberti A, Nicoli F, et al. Long-term saxagliptin treatment improves endothelial function but not pulse wave velocity and intima-media thickness in type 2 diabetic patients. High Blood Press Cardiovasc Prev. 2017;24(4):393-400. doi:10.1007/s40292017-0215-2 
9. Stafford RS, Radley DC. National trends in antiobesity medication use. Arch Intern Med. 2003;163(9):1046-1050. doi:10.1001/ archinte.163.9.1046

10. Kang JG, Park CY, Kang JH, Park YW, Park SW. Randomized controlled trial to investigate the effects of a newly developed formulation of phentermine diffuse-controlled release for obesity. Diabetes Obes Metab. 2010;12(10):876-882. doi:10.1111/j.14631326.2010.01242.x

11. Srivastava G, Apovian CM. Current pharmacotherapy for obesity. Nat Rev Endocrinol. 2018;14(1):12-24. doi:10.1038/nrendo.2017.122

12. Ballinger A. Orlistat in the treatment of obesity. Expert Opin Pharmacother. 2000;1(4):841-847. doi:10.1517/14656566.1.4.841

13. Torgerson JS, Hauptman J, Boldrin MN, Sjöström L. XENical in the prevention of diabetes in obese subjects (XENDOS) study: a randomized study of orlistat as an adjunct to lifestyle changes for the prevention of type 2 diabetes in obese patients. Diabetes Care. 2004;27(1):155-161. doi:10.2337/diacare.27.1.155

14. Browne CD, Hindmarsh EJ, Smith JW. Inhibition of endothelial cell proliferation and angiogenesis by orlistat, a fatty acid synthase inhibitor. FASEB j. 2006;20(12):2027-2035. doi:10.1096/fj.05-5404com

15. Kridel SJ, Axelrod F, Rozenkrantz N, Smith JW. Orlistat is a novel inhibitor of fatty acid synthase with antitumor activity. Cancer Res. 2004;64(6):2070-2075. doi:10.1158/0008-5472.CAN-03-3645

16. Halpern B, Oliveira ES, Faria AM, et al. Combinations of drugs in the treatment of obesity. Pharmaceuticals. 2010;3(8):2398-2415. doi: $10.3390 / \mathrm{ph} 3082398$

17. Corretti MC, Anderson TJ, Benjamin EJ, et al. Guidelines for the ultrasound assessment of endothelial-dependent flow-mediated vasodilation of the brachial artery: a report of the International Brachial Artery Reactivity Task Force. J Am Coll Cardiol. 2002;39 (2):257-265. doi:10.1016/s0735-1097(01)01746-6

18. Ras RT, Fuchs D, Koppenol WP, et al. The effect of a low-fat spread with added plant sterols on vascular function markers: results of the Investigating Vascular Function Effects of Plant Sterols (INVEST) study. Am J Clin Nutr. 2015;101(4):733-741. doi:10.3945/ ajcn.114.102053

19. Matsui S, Kajikawa M, Hida E, et al. Optimal target level of low-density lipoprotein cholesterol for vascular function in statin naive individuals. Sci Rep. 2017;7(1):8422. doi:10.1038/s41598-017-09043-1

20. Muls E, Kolanowski J, Scheen A, Van Gaal L. The effects of orlistat on weight and on serum lipids in obese patients with hypercholesterolemia: a randomized, double-blind, placebo-controlled, multicentre study. Int $J$ Obes Relat Metab Disord. 2001;25(11):1713-1721. doi:10.1038/sj.ijo.0801814

21. Wadden TA, Berkowitz RI, Womble LG, Sarwer DB, Arnold ME, Steinberg CM. Effects of sibutramine plus orlistat in obese women following 1 year of treatment by sibutramine alone: a placebo-controlled trial. Obes Res. 2000;8(6):431-437. doi:10.1038/oby.2000.53

22. Sari R, Balci MK, Cakir M, Altunbas H, Karayalcin U. Comparison of efficacy of sibutramine or orlistat versus their combination in obese women. Endocr Res. 2004;30(2):159-167. doi:10.1081/ERC200027356
23. Erdmann J, Lippl F, Klose G, Schusdziarra V. Cholesterol lowering effect of dietary weight loss and orlistat treatment-efficacy and limitations. Aliment Pharmacol Ther. 2004;19(11):1173-1179. doi:10.1111/j.1365-2036.2004.01966.x

24. Sekuri C, Tavli T, Avsar A, Sozcuer H, Uyanik BS, Ari Z. The acute effect of orlistat on endothelial function in young obese women. Int J Clin Pharmacol Res. 2003;23(4):111-117.

25. Liu J, Sun N, Yang S, Ma Z, Yang J. Effect of orlistat-assisted weight loss on endothelium-dependent vasodilation in obese Chinese subjects with hypertension. Clin Exp Hypertens. 2010;32(6):395-399. doi:10.3109/10641961003667906

26. Dinh QN, Drummond GR, Sobey CG, Chrissobolis S. Roles of inflammation, oxidative stress, and vascular dysfunction in hypertension. Biomed Res Int. 2014;2014:406960. doi:10.1155/ 2014/406960

27. Chatzizisis YS, Coskun AU, Jonas M, Edelman ER, Feldman CL, Stone PH. Role of endothelial shear stress in the natural history of coronary atherosclerosis and vascular remodeling: molecular, cellular, and vascular behavior. $J$ Am Coll Cardiol. 2007;49 (25):2379-2393. doi:10.1016/j.jacc.2007.02.059

28. Lumeng CN, Saltiel AR. Inflammatory links between obesity and metabolic disease. $J$ Clin Invest. 2011;121(6):2111-2117. doi: $10.1172 /$ jci57132

29. Samuelsson L, Gottsater A, Lindgarde F. Decreasing levels of tumour necrosis factor alpha and interleukin 6 during lowering of body mass index with orlistat or placebo in obese subjects with cardiovascular risk factors. Diabetes Obes Metab. 2003;5(3):195-201. doi:10.1046/ j.1463-1326.2003.00264.x

30. Steinberg HO, Tarshoby M, Monestel R, et al. Elevated circulating free fatty acid levels impair endothelium-dependent vasodilation. J Clin Invest. 1997;100(5):1230-1239. doi:10.1172/jci119636

31. Kim F, Tysseling KA, Rice J, et al. Free fatty acid impairment of nitric oxide production in endothelial cells is mediated by IKKbeta. Arterioscler Thromb Vasc Biol. 2005;25(5):989-994. doi:10.1161/01. ATV.0000160549.60980.a8

32. Esenabhalu VE, Schaeffer G, Graier WF. Free fatty acid overload attenuates $\mathrm{Ca} 2+$ signaling and $\mathrm{NO}$ production in endothelial cells. Antioxid Redox Signal. 2003;5(2):147-153. doi:10.1089/ 152308603764816505

33. Zhang WY, Schwartz E, Wang Y, Attrep J, Li Z, Reaven P. Elevated concentrations of nonesterified fatty acids increase monocyte expression of CD11b and adhesion to endothelial cells. Arterioscler Thromb Vasc Biol. 2006;26(3):514-519. doi:10.1161/01.atv.000020 0226.53994 .09

34. Feron O, Dessy C, Moniotte S, Desager JP, Balligand JL. Hypercholesterolemia decreases nitric oxide production by promoting the interaction of caveolin and endothelial nitric oxide synthase. J Clin Invest. 1999;103(6):897-905. doi:10.1172/jci4829

Diabetes, Metabolic Syndrome and Obesity: Targets and Therapy

Dovepress

\section{Publish your work in this journal}

Diabetes, Metabolic Syndrome and Obesity: Targets and Therapy is an international, peer-reviewed open-access journal committed to the rapid publication of the latest laboratory and clinical findings in the fields of diabetes, metabolic syndrome and obesity research. Original research, review, case reports, hypothesis formation, expert opinion and commentaries are all considered for publication. The manuscript management system is completely online and includes a very quick and fair peer-review system, which is all easy to use. Visit http://www.dovepress.com/testimonials.php to read real quotes from published authors. 